\title{
Testing Russian version of Positive Thinking Scale: some preliminary results
}

Lada A. Alexandrova, Moscow State University of Psychology and Education

Inna V. Lvova, Kuzbass Regional Institute of Advanced Training and Retraining of specialists of Education

\section{BACKGROUND}

The study is based on integration of methodological approaches of positive psychology for wellbeing and optimal functioning (E. Diener, M Csikszentmihalyi ),,self-determination theory ideas on motivation and autonomous regulation (E. Deci, R. Ryan K. Sheldon) with contemporary ideas of Russian psychology of Personality potential and personality resources proposed by D. Leontiev

\section{AIM}

The study pursued several purposes. First, we tested the Russian version of Positive Thinking Scale (Diener, 2009). Our second purpose was to assess positive thinking in teachers as a form of their subjective wellbeing manifestation

\section{SAMPLE}

237 schoolteachers of Kemerovo region (Siberia), age $25-68, M=45$, st.dev. $=10$

\section{METHODS}

As a central method Russian version of Positive Thinking Scale (PTS) was used (Diener, 2009), with all its original 22 items grouped into two subscales: first scale of positively and second one negatively formulated statements. PTS was used in two ways: as separate subscales and as a sum of both scales. we applied four-level Likert-type scale, checking the level of respondents' agreement with items. SPSS was used for data statistical analysis. Cronbach's alpha $=0.72$ for positively formulated items' scale and Cronbach's alpha $=0.67$ for negatively formulated items' scale were found. We also calculated the difference between them - as indicator of relational prevalence of positive or negative thinking style. .Additional methods

- SWLS - satisfaction with life scale (Diener, Emmons, Larsen, Griffin, 1985)

- Subjective vitality scale (Ryan, Frederick, 1997)

- Noetic orientations test (Leontiev, 1992 - a modification of Purpose-in-Life test by J. Crumbaugh \& L. Macholick)

- Hardiness Survey (Maddi, 2001)

- MSTAT-I Multiple Stimulus Types Ambiguity Tolerance-1) (McLain 1993).

- COPE ( Carver, Scheier, Weintraub, 1989)

- Generalized self-efficacy scale (Schwarzer, R., \& Jerusalem,1995).

- Measures of motivation for learning and work, based on self-determination theory approach (Gordeeva et al., 2014, 2017 )

- Flow Short Scale ((Engeser, Rheinberg, 2008)

- Work satisfaction and work engagement measures

\section{RESULTS}

Factor analysis (fragment)

Factor Loadings (Unrotated) Extraction: Principal components (Marked loadings are $>, 700000)$

\begin{tabular}{|l|r|}
\hline \multicolumn{2}{|c|}{$>$,700000) } \\
\hline Variables & Factor 1 \\
\hline SWLS & $-0,40$ \\
\hline self-efficacy & $-0,59$ \\
\hline Vt-d & $\mathbf{- 0 , 7 1}$ \\
\hline Hardiness & $\mathbf{- 0 , 9 0}$ \\
\hline Sense of life & $\mathbf{- 0 , 8 5}$ \\
\hline Positive thinking & $\mathbf{- 0 , 7 7}$ \\
\hline Tolerance to ambiguity & $-0,68$ \\
\hline Expl.Var & 3,62 \\
\hline Prp.Totl & 0,52 \\
\hline
\end{tabular}

PTS showed predictable interconnections with SWLS, Dispositional subjective vitality scale, Noetic orientations scales, Generalized selfefficacy scale, all scales of Hardiness Survey, Coping mechanisms, , Intrinsic/ Extrinsic motivation, Tolerance to ambiquity, Flow, Satisfaction with work, etc.

Nevertheless, the subscale of negatively formulated items showed slightly less correlation comparing with one with positive wordings. Moreover, the significant differences were found in thinking styles (positive versus negative) between respondents of different age and status and in interconnections of these styles with personality characteristics

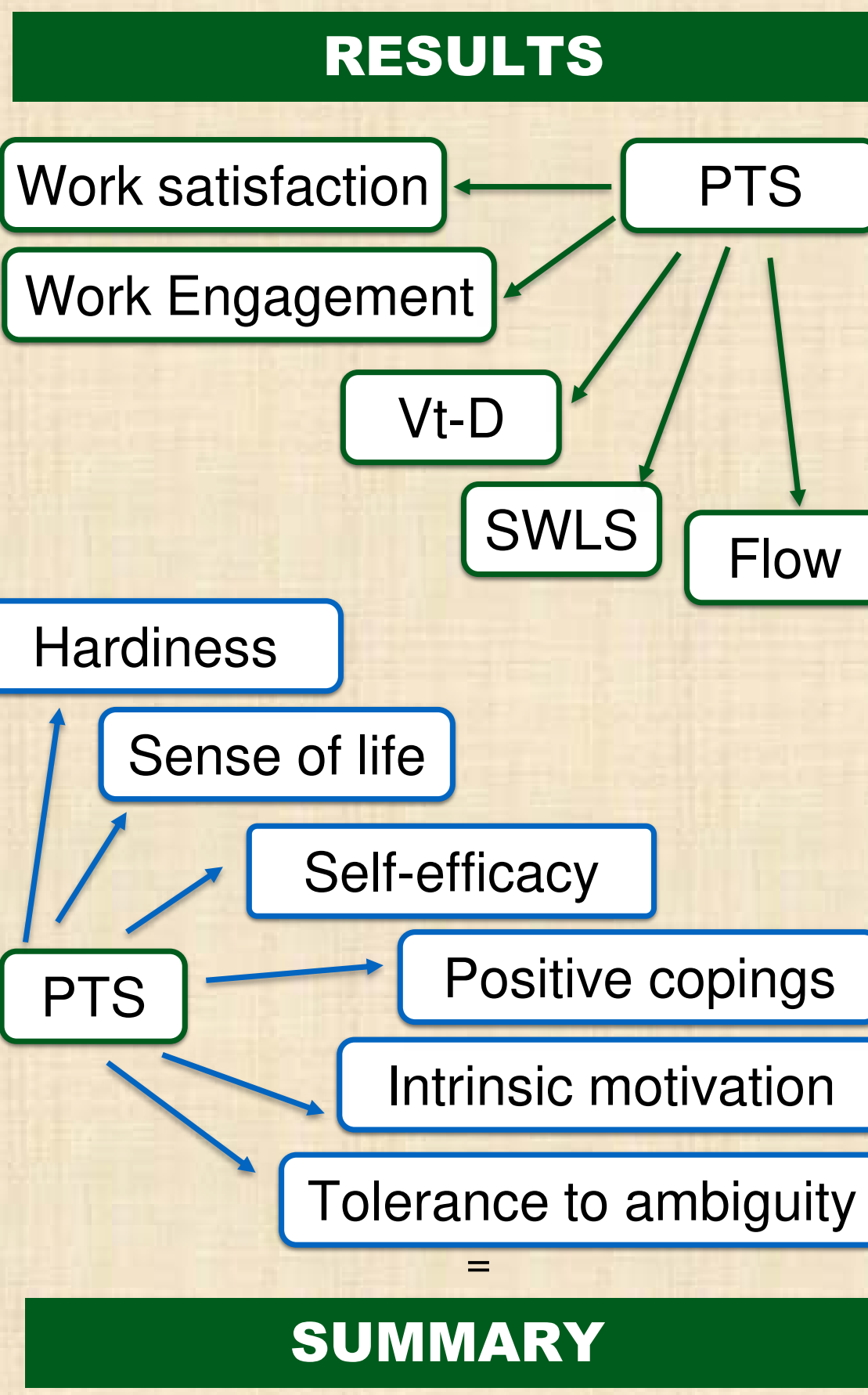

1. The Russian version of PTS scale showed itself as promising instrument for prevailing thinking style and wellbeing assessing.

2. PTS showed itself as promising instrument for measuring both types of wellbeing: eudemonic and hedonic 3/ PTS "behaves" not only as reflection of wellbeing but as a measure of personality resource 